\title{
Mulher-sujeito, mulher-poema: a imagem como configuração do feminino na poesia de Ana Paula Tavares
}

Nara Lasevicius Carreira

\section{Resumo}

Este breve estudo da lírica da poetisa angolana Ana Paula Tavares busca articular seu lugar de fala com as especificidades de uma poesia escrita por uma mulher que se coloca como tal. Para pensar tão complexa obra, escolhi um poema de cada livro da autora e o exercício interpretativo será feito, sobretudo, a partir da configuração da imagem poética e seus desdobramentos, tendo em vista a questão da mulher constituída como sujeito pleno.

Palavras-chave: Feminino - Alteridade - Poesia Angolana. 
Construção e destruição: sinônimos.

Murilo Mendes ${ }^{\mathrm{I}}$

As flores com que me vestiram

Eram só

Para arder melhor.

Ana Paula Tavares ${ }^{2}$

\section{Introdução}

Para compreender a força da poesia de Paula Tavares em seu lugar de fala Angola a partir dos anos I980 - é de grande valor recuperar alguns dados e elementos da literatura angolana que a precede.

Como explica Carmem Lucia Tendó Secco, "O erotismo, nas décadas de I980, I990 e primeiros anos dos 2000, foi um elemento fundamental de resistência da poesia angolana que, para não se submeter à melancolia circundante, voltou-se para a busca libidinal das próprias entranhas" (apud CHAVES; MACEDO; VECGHIA, 2007, p. I66). A mencionada melancolia é resultado do contexto pós-independência colonial, cenário em que a luta das últimas décadas fora esvaziada pela perpetuação de inúmeros problemas do período colonial: a profunda desigualdade social, a falta de perspectivas para as camadas mais pobres, a fragmentação do poder com os crescentes conflitos entre os diferentes grupos que, apesar das já antigas diferenças, lutaram "juntos" pela libertação do país do jugo português (MPLA e Unita, entre outros). A exaltação do guerrilheiro - figura central da literatura produzida em meio à guerra de libertação - não era mais possível: como glorificar uma batalha entre irmãos, entre pessoas do mesmo povo? O caráter heroico não valia mais para tais guerrilheiros, a violência não era mais uma resposta justa a séculos de exploração e barbárie de Portugal. Era, então, um gesto suicida de uma nação recém-liberta que precisava se articular, para que o conserto de tanto tempo sob a colonização pudesse ser realizado.

I MENDES, I994, p. I.27I-I.272.

2 Do poema Ex-votos (2003) apud TAVARES, Ana Paula. Amargos como os frutos: poesia reunida. Rio de Janeiro: Pallas, 20II, p. I58 (todas as referências dos poemas de Tavares constam dessa edição). 
É assim que novos rumos, novas questões começam a se configurar no fazer literário angolano; Ana Paula Tavares trouxe pela primeira vez para a literatura do país o feminino que tem voz, que não é mera sombra do masculino, o feminino que olha para si mesmo e para o mundo que o cerca. O verbo não é aleatório: a mulher cercada por um mundo sexista e opressor pode, então, dizer, saltar, gozar. Antes de iniciarmos nossa leitura de seus poemas, fiquemos com as palavras de Prisca Agustoni de Almeida Pereira (apud CHAVES; MACEDO; VECGHIA, 2007, p. 316), rica contribuição para nosso exercício de reflexão:

[...] por uma parte, ela apresenta um corpo feminino amoroso, individual e não coletivizado, um corpo-sujeito e não um corpo-nação; esse eu-lírico quer agora afirmar a sua (nova) sensualidade, nova porque jamais admitida [...].

Por outra parte, o desejo encenado por Paula Tavares vai além da sua corporeidade. Trata-se do desejo de se representar, de dizer, isto é, de ser, num panorama cultural em que a palavra é o elemento mais importante, capaz de nomear todo o universo $[\ldots]$.

\section{Leitura de alguns poemas ${ }^{3}$}

Para pensar tão complexa poesia, escolhi um poema de cada livro da poetisa e o exercício interpretativo será feito, sobretudo, a partir da configuração da imagem poética e seus desdobramentos, tendo em vista a questão da mulher constituída como sujeito pleno.

\section{II.I.}

\section{O mamão}

Frágil vagina semeada

Nela se alargam as sedes

Pronta, útil, semanal

3 Os poemas que leremos são dos livros seguintes, respectivamente: (I) Ritos de passagem (I985); (II) O lago da lua (I999); (III) Dizes-me coisas amargas como os frutos (200I); (IV) Ex-votos (2003); (V) Manual para amantes desesperados (2007); (VI) Como veias finas na terra (20IO). TAVARES, Ana Paula, op. cit., 20II, p. 3I; 77; I30; I68; 202; 25I. 
Mulher-sujeito, mulher-poema

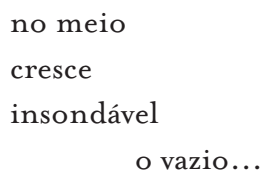

II.II.

\title{
Canto de nascimento
}

\author{
Aceso está o fogo \\ prontas as mãos \\ o dia parou a sua lenta marcha \\ de mergulhar na noite.
}

As mãos criam na água

uma pele nova

panos brancos

uma panela a ferver

mais a faca de cortar

Uma dor fina

a marcar os intervalos de tempo

vinte cabaças deleite

que o vento trabalha manteiga

a lua pousada na pedra de afiar

Uma mulher oferece à noite

o silêncio aberto

de um grito

sem som nem gesto

apenas o silêncio aberto assim ao grito

solto ao intervalo das lágrimas

As velhas desfiam uma lenta memória

que acende a noite de palavras

depois aquecem as mãos de semear fogueiras 
Uma mulher arde

no fogo de uma dor fria

igual a todas as dores

maior que todas as dores.

Esta mulher arde

no meio da noite perdida

colhendo o rio

enquanto as crianças dormem

seus pequenos sonhos de leite.

\section{II.III.}

\section{E as margens}

Respira mansa a superfície do lago

silêncio e lágrimas pesam-lhe as margens.

Uma mulher quieta

enche as mãos de sangue

cortando o azul

da superfície de vidro.

\section{II.IV.}

Trouxe as flores

Não são todas brancas, mãe

Mas são as flores frescas da manhã

Abriram ontem

E toda a noite as guardei

Enquanto coava o mel

E tecia o vestido

Não é branco, mãe

Mas serve à mesa do sacrifício

Trouxe a tacula

Antiga do tempo da avó

Não é espessa, mãe

Mas cobre o corpo 
Mulher-sujeito, mulher-poema

Trouxe as velas

De cera e asas

Não são puras, mãe

Mas podem arder toda a noite

Trouxe o canto

Não é claro, mãe

Mas tem os pássaros certos

Para seguir a queda dos dias

Entre o meu tempo e o teu.

II. $V$.

Esta manhã dói-me mais do que de costume

A pele

As escarificações

As cicatrizes

Doeu-me a noite de laços e espuma

Dói-me agora a pele

As escarificações as cicatrizes

Dói-me o teu corpo deitado

O silêncio

Os gritos em feixe

dentro de mim.

II.VI.

No olho de mel da onça
Existe a forma da cabra

O senhor do templo fechou

As portas da casa grande

$\mathrm{Na}$ minha cara

O grande senhor não sabe de mim

Das palavras que escrevo

Quando a noite chega

O senhor do templo fechou a porta

Sem aceitar as oferendas de sal 


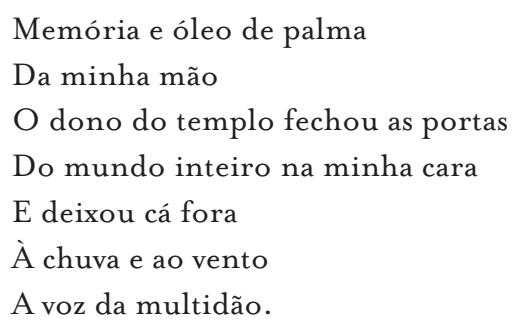

Falando de um lugar de opressão e silenciamento da voz feminina, é notável nos poemas que aqui lemos a consciência da poetisa do apropriar-se do espaço da escrita, instaurando sua identidade e circunscrevendo seu corpo no corpo do poema. Cada um dos poemas traz, de modos diversos, alguma dor, alguma cicatriz; contudo, arrisco dizer que a possibilidade de falar dessa dor e dessa cicatriz confere uma força e uma dignidade retomadas que se sobrepõem ao sofrimento desse corpo de mulher.

Pensemos o primeiro poema transcrito, $O$ mamão. A concisão contribui para a grandeza do texto na medida em que a imagem poética nele constituída transborda as margens do poema. A escolha de uma fruta como significante de uma parte do corpo traz uma pluralidade de leituras que nos cabe refletir a respeito. Há o aspecto visual, sensorial que o alimento desperta - familiar à nossa cultura, o mamão é algo que podemos ver, tocar, provar, sentir o cheiro -, aspecto que também se encontra na analogia que o poema faz: o mamão remete à vagina. Assim, passamos a outra instância da imagem: a vagina, tal como o mamão, pode ser vista, tocada, provada - para irmos ao limite, recuperando o termo vulgar, comida. Tais relações invocam, então, a presença do outro, aquele que vê, toca, prova a vagina. É pela presença oblíqua (embora, em certa medida, explícita) desse outro que se instaura a tensão: a primeira característica enunciada do órgão feminino é "frágil"; tal fragilidade é contraposta, violentamente, no verso seguinte: "Pronta, útil, semanal", condições impostas pelo outro - nada indica o consentimento da mulher dona da vagina. Paula Tavares desloca, então, o poema para outro espaço (não é por acaso a distância entre a primeira e a segunda estrofe e, mais ainda, o verso final, isolado): o espaço da intimidade feminina; a instância íntima é a mulher configurada sujeito, sujeito insondável, num vazio ambíguo - pode ser pelo esvaziamento que a ação sobre seu corpo provoca, pode ser uma modalidade da paz, do perder-se em si mesma, perda que significa conquista.

O segundo, Canto de nascimento, lança-nos a outro lugar, o poema traz uma aura a uma só vez mítica e cotidiana. O primeiro dístico anuncia o tom - começa um ritual: "Aceso está o fogo / prontas as mãos". Nas entrelinhas 
de passagens do dia a dia, "uma dor fina" é pontuada a cada verso, as marcas da violência que se consumará estão nos verbos - "ferver", "cortar", "afiar". Quando entramos na sétima parte, a violência prenunciada emerge com toda força e clareza. Esta última palavra é reveladora: todo o poema é construído em torno de imagens de luz: desde o "nascimento" do título - remontando a "dar à luz" - temos o fogo, o dia, a água (cúmplice da imagem que se projeta, da imagem criada), os panos brancos, o leite: o dia prepara o ritual para a noite do sacrifício; o parto converte-se em figuração desse processo ambíguo que perpassa a lírica de Ana Paula Tavares - ruptura e continuidade, em simultâneo.

\author{
Uma mulher oferece à noite \\ o silêncio aberto \\ de um grito \\ sem som nem gesto \\ apenas o silêncio aberto assim ao grito \\ solto ao intervalo das lágrimas
}

Quando a voz é abafada pela violência do outro (novamente...), o silêncio é a escolha possível, que se reveste de profunda significação, é um silêncio aberto e solto; o silêncio convertido em poema é o mais terrível grito que essa mulher pode dar.

O poema passa então a outro momento: essa história de silêncio subversivo é inserida num conjunto maior, o conjunto da tradição. Faz parte da história das velhas que costuram a memória, grande tecido transformado em fogo, elemento que marcará o corpo na penúltima estrofe. Como é possível imaginar, tal marca traz dor à mulher, contudo a resistência está no adjetivo que a poetisa confere à dor - "Uma mulher arde / no fogo de uma dor fria"; é pela antítese que a mulher pode resistir, recurso de linguagem também empregado no verso que encerra o quadro, "colhendo o rio". É pelo frio e pela água que a mulher investe contra o fogo que condena seu corpo. A violência que atravessa o poema depara então com o dístico final: "enquanto as crianças dormem / seus pequenos sonhos de leite". A ternura da imagem mistura-se à melancolia da repetição, as crianças são as fogueiras semeadas pelas velhas, pela tradição, à qual Paula Tavares referencia, imprimindo, porém, sua ressignificação (porque assume a postura crítica), dada pela voz que se coloca no poema.

O silêncio e a água são presenças também em nosso terceiro poema, E as margens, presenças pesadas que se contrapõem à mansidão do primeiro verso. A respiração mansa, contudo, já está dito, é da superfície - nas margens está 
indicado o que essa água (essa vida, talvez) contém. O engodo da superfície é quebrado (afinal é de vidro) pela "mulher quieta", que fala no poema por meio de seu sangue. Aqui, como em outros lugares, Paula Tavares recupera os elementos do mundo que a rodeia, mais do que para representá-lo, para representar sua própria relação com ele, relação que implica ressignificação. $\mathrm{O}$ aditivo do título - E as margens - é uma nota silenciosa que pede atenção ao que é deixado (ou posto?) de lado.

O quarto poema, sem título, é uma canção da negatividade; com a regularidade de um refrão, todo verso iniciado com "não" é terminado com "mãe". É preciso, então, atentar para o que está sendo negado: as flores brancas, o vestido branco, a tacula espessa ${ }^{4}$, as velas puras, o canto claro. A pureza que reside em cada uma das coisas - explicitada nas velas, instrumentos de luz não é possível; a negação não é rebeldia, mas a constatação de um novo tempo. Tal afirmação é feita pela explicação do que é negado; cada verso inicia com "mas": "Mas são as flores frescas da manhã", "Mas serve à mesa do sacrifício", "Mas cobrem o corpo", "Mas podem arder toda a noite", "Mas tem os pássaros certos". Vemos, assim, como Paula Tavares se reporta ao ritualístico, à cultura atemporal em que está inserida (cultura encarnada na figura da mãe, fonte de vida - e perpetuação), referenciando de modo que não se limita a dizer em seu tom o canto da tradição e da memória, mas que atualiza de seu lugar de enunciação: coloca-se o tempo inteiro como uma mulher que se assume como tal e reivindica uma voz e uma reflexão próprias.

Trouxe o canto
Não é claro, mãe
Mas tem os pássaros certos
Para seguir a queda dos dias
Entre o meu tempo e o teu.

No quinto poema, igualmente sem título, a violência aparece de forma mais pungente, comparado aos outros que lemos. A força sintética junto às repetições impede que desviemos o olhar do sofrimento da mulher; o eu-lírico feminino que fala da dor da manhã indica o alastramento dessa dor - está na pele, nas escarificações, nas cicatrizes - para, em seguida, narrar como a dor se instaurou sobre seu corpo: foi na noite que passou, "noite de laços e espumas",

4 Segundo o dicionário Priberam: "Árvore africana cuja madeira tem veios de carmesim brilhante e é muito apreciada e usada em tinturaria". Disponível em: http://www.priberam.pt; Acesso em: 20/06/20I3. 
imagem delicada para referir o ato sexual, delicadeza que se configura, como temos observado, em sua forma de resistir. Pontuado o passado, o eu-lírico repete a narração da dor presente, intensificada pela consciência do silêncio que fere - "os gritos em feixe", ou seja, o grito atado, impedido de se fazer ouvir. A violência naturalizada que incessantemente vitima a mulher em todas as instâncias do ser (principalmente na do próprio ser, posto sempre como objeto, nunca sujeito) recebe a mais dura e amarga resposta, esse silêncio desmascarado pela voz que se coloca no poema, voz que, no momento em que é anunciada, é o desfazimento do feixe.

Chegamos enfim ao último poema escolhido, que se abre com significativa epígrafe: "No olho de mel da onça / Existe a forma da cabra". O efeito antitético constitui-se pelo poder do desvio provocado pelo emparelhamento de tão diferentes animais. Ímpeto e força contrapõem-se à passividade e à doçura; transpostas tais características para o ser feminino, temos o natural contraposto ao social, ou seja, aquilo que a mulher é, que ela podeser, torna-se obstruído por aquilo que ela tem que ser. Não é por acaso que o poema traz um sujeito feminino que se dirige a uma espécie de entidade triplamente poderosa e opressora: é homem, é senhor e é do templo, remetendo à histórica misoginia encarnada nas religiões. Os três primeiros versos, desalentados, dão a dimensão do autoritarismo e da brutalidade com que a mulher que fala é tratada por esse homem gigantesco. Contudo, nos três versos que seguem, reside a grande força dessa mulher, força que se concentra na ignorância de seu opressor:

O grande senhor não sabe de mim

Das palavras que escrevo

Quando a noite chega

A melancolia persiste, o grande senhor continua a negar a voz, a negar qualquer relação possível, a não aceitar o que vem das mãos femininas, a fechar indefinidamente as portas. Os versos finais, com o desalento acentuado, são os versos da mulher que reconhece o peso que insiste em esmagá-la, excluí-la, colocá-la à margem. Entretanto, vemos que o que resta a essa mulher não é pouca coisa: é a chuva, é o vento e é a multidão (sendo que este último elemento ganha relevância na medida em que a poética de Tavares se ancora em um pensamento de assimilação e, ao mesmo tempo, reconfiguração da cultura de seu povo, das tradições angolanas). Dentro de uma poesia que opera com ressignificações, com o construir e o destruir, podemos esperar um rearranjo, uma nova costura daquilo que o mundo lhe dá, um novo que se chama liberdade para um sujeito chamado mulher. 


\title{
III. Reflexão final (nos limites dessas páginas...)
}

\begin{abstract}
Persigo a palavra, um poema, apenas um poema para trabalhar todos os dias até conseguir que se leia pelo avesso. Com ele, podia iluminar as sombras da vida, criar harmonia na desordem, voltar à palavra primeira como aquela que inaugura as grandes costuras dos veludos teke (as águas que separam o céu e a terra, e as águas que dividem o mundo habitável do mundo subterrâneo). Seriam precisas muitas mais vidas e conhecimentos de forja que não herdei das mais velhas. Resta-me continuar a tecer e a celebrar estes momentos de amizade, em que poemas (mesmo os antigos) e pessoas se misturam em templos de afeto cumpridos nesta vida (TAVARES, apud SECGO; SALGADO; JORGE, 2010, p. 59-60).
\end{abstract}

O avesso perseguido por Ana Paula Tavares é semeado em cada poema que lemos, retalhos de um grande tecido de memória e subversão; semeado no próprio ato da escrita, apropriado por mãos femininas, revolucionário em si, mas que se desdobra em outros avessos, em outras revoluções. Cada poema nascido desse corpo de mulher é um gesto de empoderamento, uma reescritura de imagens dadas pela tradição, ato que a uma só vez recupera e reinventa a força da imagem poética como recurso da linguagem da poesia. Murilo Marcondes de Moura (I994, p. 27-28), em seu estudo sobre Murilo Mendes, tece considerações sobre a obra do poeta mineiro que dialogam com o que viemos discutindo; há uma relação negativa de sua lírica com a realidade, "como se o florescimento daquela só pudesse ocorrer dentro da transfiguração desta". Esse florescimento se dá em condições que privilegiam a imagem como canal transformador. Marcondes de Moura vê aí a influência de Reverdy: há uma "ênfase na autonomia da linguagem poética" - isso significa que a arte deve ser de criação "e não de reprodução ou de interpretação". Dessa forma, podemos ler na poética de Paula Tavares as marcas de um feminino que reorganiza o mundo, transfigura o real pelo avesso dos signos, dos elementos que a circundam, do poder que lhe tira a voz.

\section{Referências bibliográficas}

MENDES, Murilo. Marcel Duchamp (dos Retratos-relâmpago). In: Idem. Poesia completa e prosa. Rio de Janeiro: Nova Aguilar, I994.

MOURA, Murilo Marcondes de. Murilo Mendes: a poesia como totalidade. São Paulo: Edusp, I994. 
PEREIRA, Prisca Agustoni de Almeida. A circularidade inacabada de Paula Tavares. In: CHAVES, Rita; MACEDO, Tania; VECGHIA, Rejane (org.). A kinda e a misanga: encontros com a literatura angolana. São Paulo: Cultura Acadêmica; Luanda, Angola: Nizla, 2007.

SECCO, Garmem Lucia Tendó. A poesia angolana atual e a procura de outras formas de politização. In: CHAVES, Rita; MACEDO, Tania; VECGHIA, Rejane (org.). A kinda e a misanga: encontros com a literatura angolana. São Paulo: Cultura Acadêmica; Luanda, Angola: Nizla, 2007.

TAVARES, Ana Paula. Amargos como os frutos: poesia reunida. Rio de Janeiro: Pallas, 201 .

Ritos de passagem. In: SEGGO, Carmen Lucia Tendó; SALGADO, Maria Teresa; JORGE, Silvio Renato. Pensando África: literatura, arte, cultura e ensino. Rio de Janeiro: Fundação Biblioteca Nacional, 20 Io.

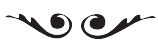

Nara Lasevicius Carreira - Graduada em Letras pela Universidade de São Paulo em 20I4. Mestranda em Estudos Comparados de Literaturas de Língua Portuguesa pela Universidade de São Paulo. 